Classification

Physics Abstracts

61.10Lx $-61.16 \mathrm{Bg}-68.35-\mathrm{p}-73.20 \mathrm{At}-82.80-\mathrm{d}-82.80 \mathrm{Pv}$

\title{
Electron Energy-Loss Near-Edge Structure of Metal-Alumina Interfaces
}

\author{
Christina Scheu $\left({ }^{1}\right)$, Gerhard Dehm $\left({ }^{1}\right)$, Harald Müllejans $\left({ }^{1}\right)$, Rik Brydson $\left({ }^{2}\right)$ and \\ Manfred Rühle $\left({ }^{1}\right)$ \\ $\left({ }^{1}\right)$ Max-Planck-Institut für Metallforschung, Institut für Werkstoffwissenschaft SeestraBe 92, 70174 \\ Stuttgart, Germany \\ $\left(^{2}\right)$ Department of Materials Science and Engineering, University of Surrey, Guildford GU2 5XH, \\ U.K.
}

(Received October 17; accepted February 5, 1994)

\begin{abstract}
The physical properties of metal-ceramic composites are strongly affected by the local chemistry and atomic bonding across the interface. Information on both are contained in the energy-loss near-edge structure. The spectral component specific for the interface can be obtained by the spatial- difference technique. This method was applied for the investigation of two different interfaces, namely $\mathrm{Al} / \mathrm{Al}_{2} \mathrm{O}_{3}$ and $\mathrm{Cu} / \mathrm{Al}_{2} \mathrm{O}_{3}$. The $\mathrm{Al}-L_{2,3}$ edge at the $\mathrm{Al} / \mathrm{Al}_{2} \mathrm{O}_{3}$ interface shows a characteristic energy-loss near-edge structure which was compared to multiple scattering calculations for $\mathrm{Al}\left(\mathrm{O}_{3} \mathrm{Al}\right)$ tetrahedra with various $\mathrm{Al}-\mathrm{Al}$ bond lengths. Good agreement with the experimental data was found for a cluster with an $\mathrm{Al}-\mathrm{Al}$ bond length larger than the $\mathrm{Al}-\mathrm{O}$ distance which is nearly that of amorphous $\mathrm{Al}_{2} \mathrm{O}_{3}$. No interface-specific component could be detected at the $\mathrm{Al}-L_{2,3}$ edge of the $\mathrm{Cu} / \mathrm{Al}_{2} \mathrm{O}_{3}$ interface. However, the energy-loss near-edge structure of the $\mathrm{Cu}-L_{2,3}$ edge indicates that $\mathrm{Cu}$ exists at the interface in a $\mathrm{Cu}^{1+}$ state and that the chemical bond is established at the interface between $\mathrm{Cu}$ and $\mathrm{O}$ atoms.
\end{abstract}

\section{Introduction}

The properties of metal-ceramic composites depend significantly on the structure and composition of the interface between the two materials. It is most desirable to understand the bonding and the electronic structure of the interface at the atomic level. Both are important for applications of structural composites and in electronic packaging systems. Studies of electron energy-loss spectroscopy (EELS) provide useful information about all these aspects. The chemical composition can be determined from the intensity of the ionization edges which are element specific. Furthermore, the energy-loss near-edge structure (ELNES) in the region from the onset of the edge to approximately $20-30 \mathrm{eV}$ above the edge contains information about the bonding and the electronic structure [1]. Different oxidation states of metals can be distinguished either by 
chemical shifts or by changes in the shape of the absorption edge. In many materials ELNES is also very sensitive to short-range order such as bond distances, coordination and type of nearest neighbours which is known as "coordination fingerprint" [2]. Therefore, simple structural models can be obtained either by comparing the measured ELNES with reference materials of known coordination or calculated ELNES.

The ELNES of atomically abrupt interfaces can generally not be measured on its own because of the spatial extent of the electron beam. Even with a dedicated scanning transmission electron microscope (STEM) it is possible only in special cases to obtain spectroscopic information from single columns of atoms [3]. Therefore, electron energy-loss spectra measured with the electron beam positioned on an interface usually contain not only the signal from the interface but also contributions from the surrounding bulk materials. To extract the interface-specific components the spatial difference technique can be used $[4,5]$. This method acquires in addition to the spectrum with the beam positioned on the interface two reference spectra under identical conditions with the beam positioned on the bulk materials on both sides of the interface (Fig. 1). The contributions of the bulk materials contained in the interface spectrum are then removed by subtracting the reference spectra. These have to be scaled before subtraction because their absolute contributions are not known. The resulting difference spectrum represents the ELNES arising from the interfacial atoms. So far the spatial difference technique has been applied to grain boundaries in $\mathrm{Al}_{2} \mathrm{O}_{3}$ [6] and metal-ceramic interfaces [7, 8].

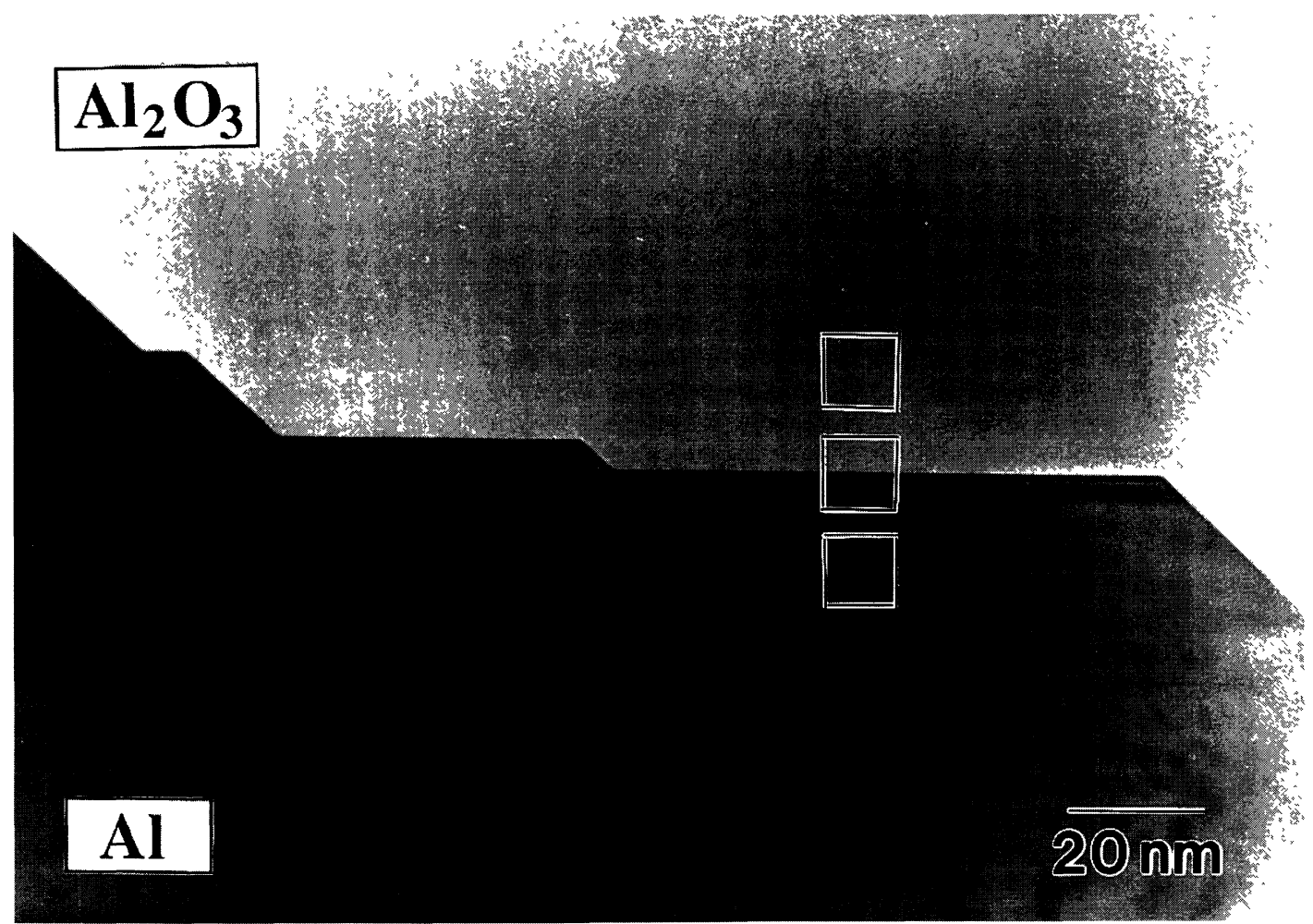

Fig. 1. - Typical TEM bright field image of a facetted aluminium-alumina interface. To illustrate the spatial difference technique three windows are drawn in the same manner as typically used for the measurements. The spectra shown in Figure 2 however, were not acquired at this particular interface. 
In the present work ELNES is applied to two metal-ceramic interfaces, one in a real, structural metal-ceramic composite prepared by infiltration of porous alumina with liquid aluminium [9], and the other in a thin copper film deposited on alumina by molecular beam epitaxy (MBE) [10].

Recently, investigations of the $\mathrm{Al} / \mathrm{Al}_{2} \mathrm{O}_{3}$ system have been carried out on interfaces prepared by sessile drop techniques [11], partial oxidation of aluminium [12], and infiltration of $\mathrm{Al}_{2} \mathrm{O}_{3}$ with liquid metal [13]. In all these experiments no reaction layers were found. Electron spectroscopic methods such as low-energy electron diffraction (LEED), high-resolution electron energy-loss spectroscopy (HREELS) and X-ray induced photoemission spectroscopy (XPS) were applied to study the interface formation and growth behaviour of aluminium films evaporated on (0001) $\alpha-\mathrm{Al}_{2} \mathrm{O}_{3}$ [14]. However, detailed information about the interface structure and bonding have not yet been obtained.

More extensive studies have been carried out on the $\mathrm{Cu} / \mathrm{Al}_{2} \mathrm{O}_{3}$ system, most of them concerned with preparation methods such as eutectic bonding [15-17], solid-state bonding [16, 18], internal oxidation [19], and vapour deposition [20,21]. Depending on the processing conditions, either an atomically abrupt interface or reaction layers are formed. Possible phases in the $\mathrm{Cu}-\mathrm{Al}-\mathrm{O}$ system are the two aluminates $\mathrm{CuAlO}_{2}$ and $\mathrm{CuAl}_{2} \mathrm{O}_{4}$ [22]. Formation of these compounds at the interface is only expected for bicrystals prepared in a non reducing atmosphere [23]. From thermodynamics the formation of $\mathrm{CuAlO}_{2}\left(\mathrm{Cu}^{1+}\right)$ at the interface needs a lower temperature and oxygen partial pressure than $\mathrm{CuAl}_{2} \mathrm{O}_{4}\left(\mathrm{Cu}^{2+}\right)$ phase formation. By the equilibrium stability diagram no reaction layers should occur at $\mathrm{Cu} / \mathrm{Al}_{2} \mathrm{O}_{3}$ interfaces prepared in ultra high vacuum even at a temperature of $1000{ }^{\circ} \mathrm{C}$ [22]. Under these conditions bonding between $\mathrm{Cu} / \mathrm{Al}_{2} \mathrm{O}_{3}$ should not be a result of chemical reaction but direct chemical bonding involving only charge transfer without any mass transfer.

The direct $\mathrm{Cu} / \mathrm{Al}_{2} \mathrm{O}_{3}$ bonding was investigated for model systems with monolayer copper coverages on alumina substrates by several authors [20,21, 24]. They detected $\mathrm{Cu}-\mathrm{O}$ bonding by applying surface sensitive methods such as Auger electron spectroscopy (AES) [20, 24], reflection electron energy-loss spectroscopy (REELS) [20, 24] and ultraviolet photoelectron spectroscopy (UPS) [21]. However, the electronic structure of internal interfaces in $\mathrm{Cu} / \mathrm{Al}_{2} \mathrm{O}_{3}$ bicrystals has not yet been analyzed by spectroscopic methods.

The aim of this work was to determine the structure and bonding of $\mathrm{Al} / \mathrm{Al}_{2} \mathrm{O}_{3}$ and $\mathrm{Cu} / \mathrm{Al}_{2} \mathrm{O}_{3}$ interfaces in bulk materials. This was approached by a detailed comparison of the interfacial ELNES with calculated and measured reference spectra.

\section{Experiments}

The $\mathrm{Al} / \mathrm{Al}_{2} \mathrm{O}_{3}$ specimens were prepared by infiltration of porous alumina with liquid aluminium [9], while for the $\mathrm{Cu} / \mathrm{Al}_{2} \mathrm{O}_{3}$ system a $1.1 \mu \mathrm{m}$ thick copper film was grown epitaxially by $\mathrm{MBE}$ on a (0001) $\alpha-\mathrm{Al}_{2} \mathrm{O}_{3}$ single crystal [10]. For the $\mathrm{Al} / \mathrm{Al}_{2} \mathrm{O}_{3}$ system transmission electron microcopy (TEM) specimens were prepared by standard methods [25] and investigated by conventional TEM in a JEOL JEM 2000FX. High resolution TEM was performed on $\mathrm{Cu} / \mathrm{Al}_{2} \mathrm{O}_{3}$ cross-sectional TEM specimens in the Stuttgart JEM-ARM 1250 (JEOL) operating at $1250 \mathrm{keV}$ [26]. A detailed description of the cross-section preparation method is given in [27]. The MBE grown samples were carbon coated to avoid charging effects of the alumina in the electron microscope. For the $\mathrm{Al} / \mathrm{Al} 2 \mathrm{O} 3$ specimens no carbon coating was required because specimen charging did not occur.

EELS was carried out in a VG HB 501 dedicated STEM equipped with a cold field emission source and a parallel electron energy-loss spectrometer (Gatan 666 PEELS). For measuring the $\mathrm{Al}-L_{2,3}$ edges of both systems as well as the $\mathrm{O}-\mathrm{K}$ edge of the $\mathrm{Al} / \mathrm{Al}_{2} \mathrm{O}_{3}$ interface the beam current was $0.4 \mathrm{nA}$ at a beam diameter of $0.5 \mathrm{~nm}$ (full-width at half-maximum). The beam current was increased to $3 \mathrm{nA}$ for a better signal-to-noise ratio at the $\mathrm{Cu}-L_{2,3}$ and $\mathrm{O}-\mathrm{K}$ edge of the $\mathrm{Cu} / \mathrm{Al}_{2} \mathrm{O}_{3}$ 
interface. The corresponding beam diameter was $2 \mathrm{~nm}$. The above values for beam current and size represent the results of the microscope calibration. They were not measured at the time of the EELS experiments and therefore might have been slightly different. However, for the spatial difference technique it is only important that the beam current for all three spectra is equal. This can be assumed as each set of spectra was taken within one minute.

A dispersion of $0.1 \mathrm{eV} /$ channel was chosen for the investigation of the $\mathrm{Al} / \mathrm{Al}_{2} \mathrm{O}_{3}$ interface. The energy resolution as measured by the full-width at half-maximum of the zero loss peak was $0.6 \mathrm{eV}$. For the data acquisition of the $\mathrm{Cu} / \mathrm{Al}_{2} \mathrm{O}_{3}$ interface the dispersion was $0.2 \mathrm{eV} /$ channel and the energy resolution $0.8 \mathrm{eV}$. In our experience the whole system is stable to within one channel for the acquisition times used here. Therefore, edge onset and energy position of characteristic ELNES features are accurate within $0.1 \mathrm{eV}$ in the spectra taken at the $\mathrm{Al} / \mathrm{Al}_{2} \mathrm{O}_{3}$ interface and within $0.2 \mathrm{eV}$ for the $\mathrm{Cu} / \mathrm{Al}_{2} \mathrm{O}_{3}$ interface. All spectra were corrected for dark current of the parallel detector. The pre-edge background was extrapolated by a power law $A \cdot E^{-r}$ [28] and subtracted from the original data.

The interfaces were aligned edge on and spectra were taken with the beam scanning a $10 \times$ $12 \mathrm{~nm}^{2}$ area. In comparison to a stationary beam this reduces the beam damage and allows a manual correction of specimen drift since the interface is simultaneously imaged on the high angle annular dark field detector. Measurements with a stationary beam centered on the interface have a higher sensitivity, but the electron beam might not be accurately positioned on the interface or might drift away during data acquisition due to instability of the microscope. These problems are avoided by scanning the beam over an area. Also the exact beam diameter is not important, since it is much smaller than the scanned area. Three spectra were acquired for each interface, one from a region containing the interface and two in the bulk materials nearby (for illustration see Fig. 1). The latter two were multiplied by scaling factors and then subtracted from the spectrum obtained at the interface. The remaining spectral components reveal the ELNES of the atoms at the interface with an environment or oxidation state different from both bulk materials. The scaling factors are necessary because different numbers of bulk atoms are irradiated during the acquisition of the interface and reference spectra respectively. In this work the scaling factors were determined by trial and error using the following guidelines: selection of an energy loss region containing strong and characteristic features for the bulk materials and minimizing these contributions in the difference spectrum. In the case that a chemical shift occurs the intensity directly above the edge onset is eliminated. Care was taken that the subtraction of the reference spectra did not lead to negative intensities which are physically not allowed.

We performed multiple scattering (MS) calculations for a cluster of five atoms in order to model the ELNES of the $\mathrm{Al}-L_{2,3}$ edge measured at the $\mathrm{Al} / \mathrm{Al}_{2} \mathrm{O}_{3}$ interface using the ICXANES computer code [29]. For the interpretation of the difference spectrum of the $\mathrm{Cu} / \mathrm{Al}_{2} \mathrm{O}_{3}$ interface we used reference spectra from pure $\mathrm{CuO}$ and $\mathrm{Cu}_{2} \mathrm{O}$.

\section{Results}

3.1 $\mathrm{AL} / \mathrm{AL}_{2} \mathrm{O}_{3}$ INTERFACE. - TEM images revealed no reaction layer at the interface but faceting of the $\mathrm{Al} 2 \mathrm{O} 3$ grains was frequently observed, see Figure 1. EEL spectra were taken at such interfaces.

Figure 2 displays the three $\mathrm{Al}-\mathrm{L}_{2,3}$ edge spectra recorded with the window on the alumina matrix, the interface and the bulk $\mathrm{Al}$ metal. For illustration of the method the windows are drawn in the electron micrograph (Fig. 1) although the spectra were not taken at this particular interface. The spectrum measured at the interface obviously contains contributions from both bulk materials. These components were removed by subtracting the $\mathrm{Al}$ reference spectrum and the $\mathrm{Al}_{2} \mathrm{O}_{3}$ reference spectrum using scaling factors of 0.46 and 0.53 respectively. The scaling factor for the 


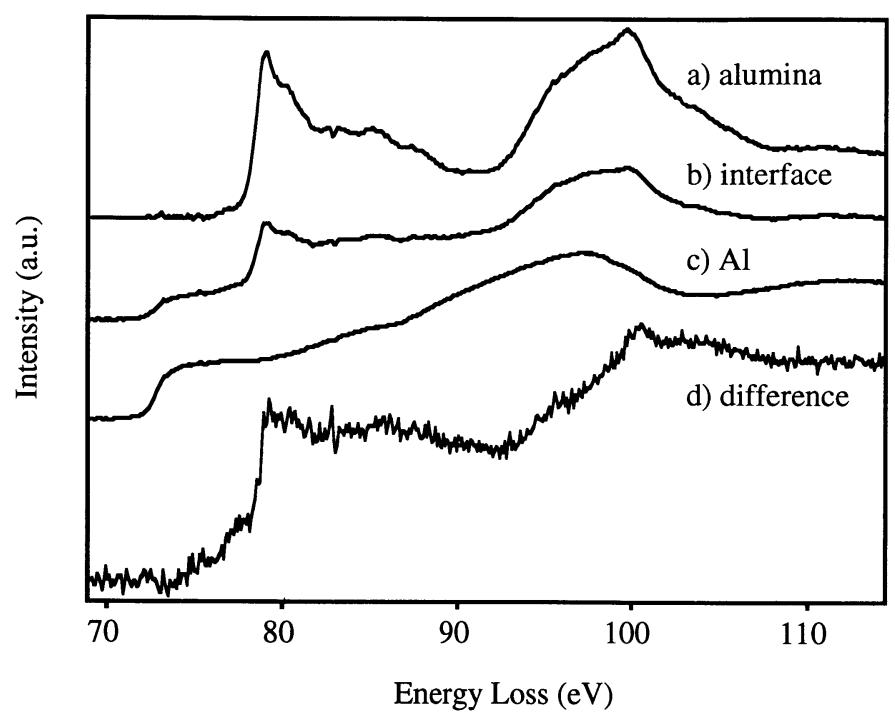

Fig. 2. - Al- $L_{2,3}$ edge ELNES from alumina infiltrated with aluminium. The spectra were recorded a) in $\mathrm{Al}_{2} \mathrm{O}_{3}$ near the interface, b) at the interface, c) in $\mathrm{Al}$ metal near the interface; d) shows the calculated difference spectrum.
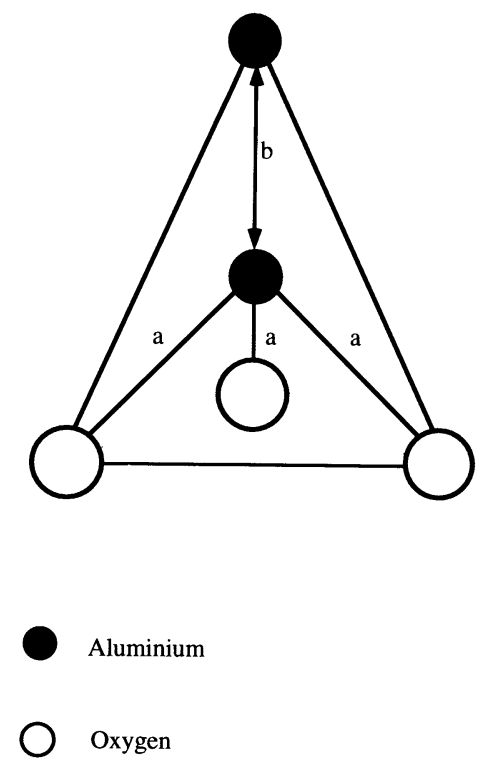

Fig. 3. - Model of the $\mathrm{Al}\left(\mathrm{O}_{3} \mathrm{Al}\right)$ cluster used for the multiple scattering calculations. The fixed bond lengths of $0.17 \mathrm{~nm}$ are labeled as a), whereas $\mathrm{b}$ ) is the distance varied during the calculations.

bulk $\mathrm{Al}$ metal contribution was chosen so that the intensity directly above the edge onset at $72 \mathrm{eV}$ was as small as possible. For the contribution of the $\mathrm{Al}_{2} \mathrm{O}_{3}$ reference spectrum the scaling factor was determined by minimizing the prominent peak at $79 \mathrm{eV}$. The remaining intensity labeled as difference spectrum represents the ELNES of the interfacial atoms having a coordination differ- 


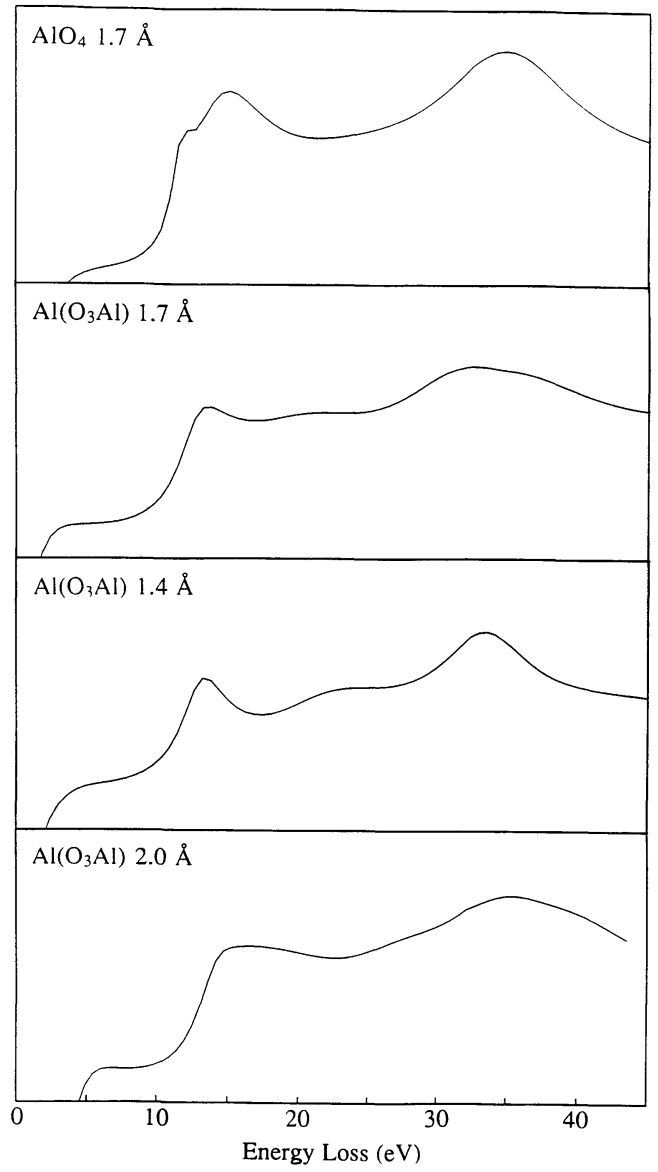

Fig. 4. - MS calculations for the $\mathrm{Al}-L_{2,3}$ ELNES of a tetrahedral $\mathrm{Al}\left(\mathrm{O}_{3} \mathrm{Al}\right)$ cluster with all three $\mathrm{Al}-\mathrm{O}$ bond lengths equal to $0.17 \mathrm{~nm}$ and the $\mathrm{Al}-\mathrm{Al}$ bond length equal to b) $0.17 \mathrm{~nm}, \mathrm{c}) 0.142 \mathrm{~nm}$ and d) $0.2 \mathrm{~nm}$. For comparison a) shows the calculations for a tetrahedral $\mathrm{AlO}_{4}$ cluster with all $\mathrm{Al}-\mathrm{O}$ distances equal to $0.17 \mathrm{~nm}$.

ent from both bulk materials.

The ELNES was calculated for different tetrahedrally coordinated clusters with a central Al atom (Fig. 3). The influence of the type of nearest neighbours is visible in Figure 4a and Figure 4b. There MS calculations for an $\mathrm{AlO}_{4}$ cluster and for an $\mathrm{Al}\left(\mathrm{O}_{3} \mathrm{Al}\right)$ cluster with four equal bond lengths of $0.17 \mathrm{~nm}$ which is nearly that of amorphous $\mathrm{Al}_{2} \mathrm{O}_{3}$ are shown. The shoulder at the low energy side of the first main peak vanishes and the second main peak is broadend for the $\mathrm{Al}\left(\mathrm{O}_{3} \mathrm{Al}\right)$ cluster. The $\mathrm{Al}-\mathrm{Al}$ bond length was then varied between $0.142 \mathrm{~nm}$ and $0.2 \mathrm{~nm}$ (Fig. 4), whereas the $\mathrm{Al}-\mathrm{O}$ distance was fixed to $0.17 \mathrm{~nm}$. Reducing the $\mathrm{Al}-\mathrm{Al}$ distance to $0.142 \mathrm{~nm}$ leads to sharper features (Fig. 4c), whereas for an increased bond length of $0.2 \mathrm{~nm}$ the structure broadens (Fig. 4d). These changes occur due to a complex interplay between symmetry loss and different phase shifts upon scattering at $\mathrm{Al}$ and $\mathrm{O}$ atoms. Best agreement with the experimental data is obtained for the cluster where the $\mathrm{Al}-\mathrm{Al}$ bond length is larger than the $\mathrm{Al}-\mathrm{O}$ distance (Fig. 4d). Only the shoulder or maybe the pre-peak below the sharp rise of the edge is not simulated by the calculations.

For the O-K edge the direct comparison of the interface spectrum with the bulk alumina spec- 


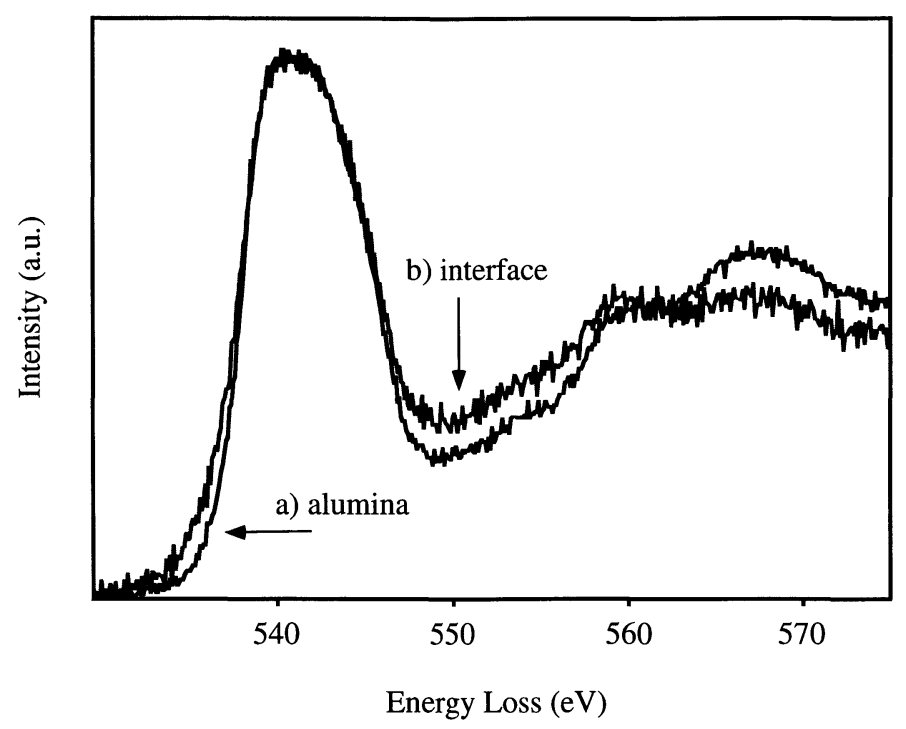

Fig. 5. - O-K edge ELNES from alumina infiltrated with aluminium. The spectra were from a) $\mathrm{Al}_{2} \mathrm{O}_{3}$ near the interface and $b$ ) the interface.

trum shows a slightly downward shift of about $0.3 \mathrm{eV}$ of the edge onset and a slight broadening of the main peak (Fig. 5).

3.2 $\mathrm{CU} / \mathrm{Al}_{2} \mathrm{O}_{3}$ INTERFACE. - The specimens were investigated in a high resolution TEM. Epitaxial growth was found with the copper (111) plane parallel to the (0001) plane of alumina and the close-packed directions of copper $<110>$ parallel to the close-packed direction in alumina [10̄0] [10]. The interface is abrupt as shown by the electron micrograph (Fig. 6). No trace of a chemical reaction layer at the interface is visible. The EEL spectra were taken at these interfaces.

The recorded $\mathrm{Al}-L_{2,3}$ edge in bulk alumina and the $\mathrm{Cu}-M_{2,3}$ edge in the bulk copper are subtracted from the interface signal (Fig. 7). The applied scaling factors were determined similarly as for the $\mathrm{Al}-L_{2,3}$ at the $\mathrm{Al} / \mathrm{Al}_{2} \mathrm{O}_{3}$ interface. This means the intensity immediately above the edge threshold at $74 \mathrm{eV}$ of the $\mathrm{Cu}-M_{2,3}$ edge and the contribution of the prominent peak at $79 \mathrm{eV}$ of the $\mathrm{Al}-L_{2,3}$ edge in bulk $\mathrm{Al}_{2} \mathrm{O}_{3}$ were minimized. Scaling factors of 0.7 for the $\mathrm{Cu}$ reference spectrum and 0.2 for the bulk $\mathrm{Al}_{2} \mathrm{O}_{3}$ spectrum were chosen. No interface-specific component exists, since the resulting difference spectrum is zero within the detection limits set by noise (Fig. 7).

Subtraction of the $\mathrm{Cu}-L_{2,3}$ edge spectrum of bulk $\mathrm{Cu}$ from the interface yields a difference spectrum which is clearly not zero (Fig. 8). It is dissimilar to the ELNES of the pure metal and contains a $L_{3}$ white line at $933 \mathrm{eV}$. To obtain this difference spectrum a scaling factor of 0.4 was used. Higher values led to negative intensities in the region of $935 \mathrm{eV}$ to $947 \mathrm{eV}$ which are physically not allowed.

The difference spectrum of the O-K edge (Fig. 9) shows that the main peak at $540 \mathrm{eV}$ is broadend and shifted to slightly lower energy-losses. Furthermore, a second prominent peak is visible at $560 \mathrm{eV}$ which is not contained in the ELNES of the O-K edge of alumina. The scaling factor for the $\mathrm{Al}_{2} \mathrm{O}_{3}$ reference spectrum was 0.35 . Larger values for the scaling factor resulted in negative intensities in the energy-loss region between $560 \mathrm{eV}$ and $590 \mathrm{eV}$. Higher energy-losses are influenced by thickness effects and therefore not considered here. 


\section{Discussion}

4.1 AL $/ \mathrm{AL}_{2} \mathrm{O}_{3}$ INTERFACE. - The shape of the $\mathrm{Al}-L_{2,3}$ ELNES is very sensitive to the coordination of the next nearest neighbours and the interatomic distances as shown by previous theoretical [30] and experimental studies [6-8]. It provides, therefore, a powerful tool to detect changes in the local coordination of the aluminium atoms at alumina interfaces. The high sensitivity to the next nearest neighbours explains why it is possible to obtain the main features of our ELNES with MS calculations using clusters of five atoms. This is true in general if the first coordination shell containing the next nearest neighbours consists of strong backscatterers such as oxygen $[2,30]$ as is the case at alumina interfaces.

It seems most likely that at the actual interface there are $\mathrm{Al}$ atoms which on one side have neighbouring $\mathrm{O}$ atoms from the alumina, whereas on the other side there are $\mathrm{Al}$ atoms belonging to the metal. Therefore, $\mathrm{O}-\mathrm{Al}-\mathrm{Al}$ linkages occur at the $\mathrm{Al} / \mathrm{Al}_{2} \mathrm{O}_{3}$ interface. The ELNES of these $\mathrm{Al}$ atoms will be the strongest contribution to the difference spectrum because their local atomic environment is clearly different from both alumina and aluminium. To model the difference spectrum we performed MS calculations for simple $\mathrm{Al}\left(\mathrm{O}_{3} \mathrm{Al}\right)$ tetrahedra. We found best agreement between the measured and calculated ELNES for the cluster consisting of a central $\mathrm{Al}$ atom tetrahedral coordinated with three $\mathrm{O}$ atoms and one $\mathrm{Al}$ atom with a $\mathrm{Al}-\mathrm{Al}$ bonding distance of $0.2 \mathrm{~nm}$ and a $\mathrm{Al}-\mathrm{O}$ bond length of $0.17 \mathrm{~nm}$. This suggests that such structural units occur at the interface. However, the good agreement between the calculated and measured ELNES does not exclude the existence of further structural units at the interface with different coordination and different bond lengths. Further calculations are necessary to clarify this.

We found a reduced coordination for the interfacial $\mathrm{Al}$-atoms compared to the octahedral coordination of the Al-atoms in bulk alumina [30]. Similar results were obtained in studies of other metal-alumina interfaces [7, 8]. The ELNES of the difference spectrum shows no strong features compared to the prominent sharp peaks visible in the ELNES of bulk alumina. This is due to the decreased number of nearest-neighbour scatterers at the interface [2]. The measured difference spectrum contains a shoulder/pre-peak below the sharp rise of the intensity. It may occur from

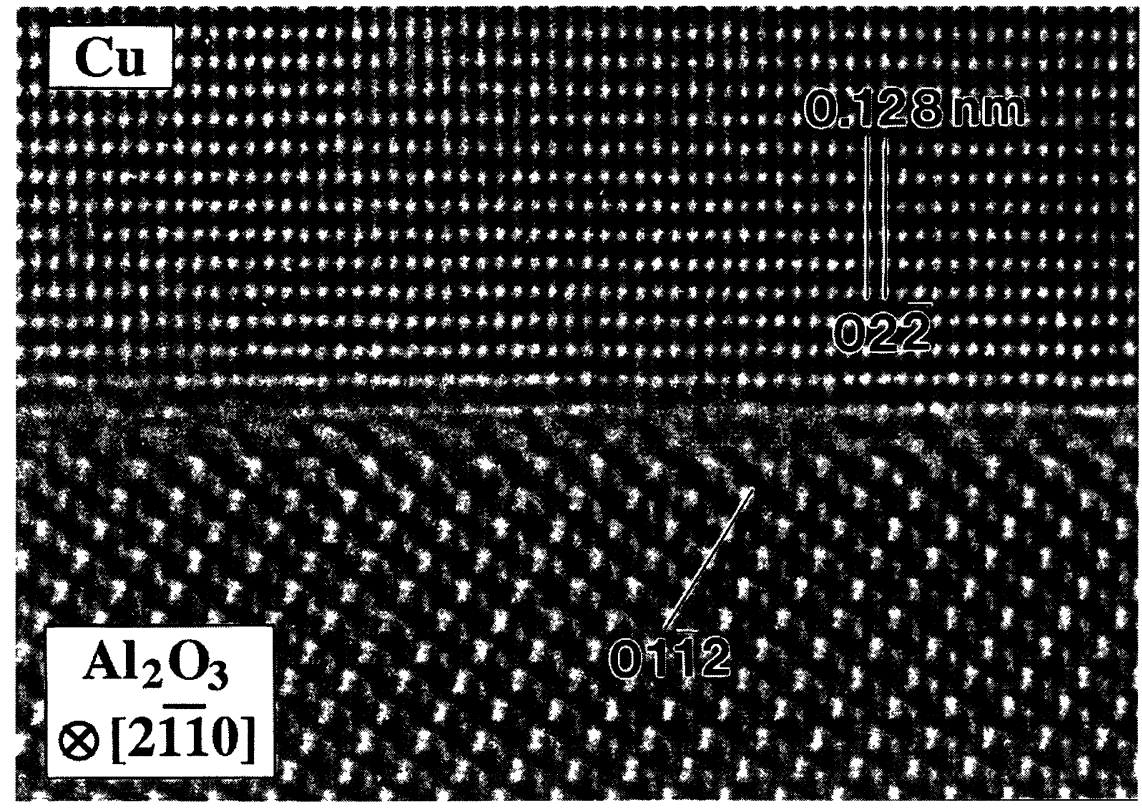

Fig. 6. - High resolution micrograph of the atomically sharp copper-alumina interface grown by MBE. 


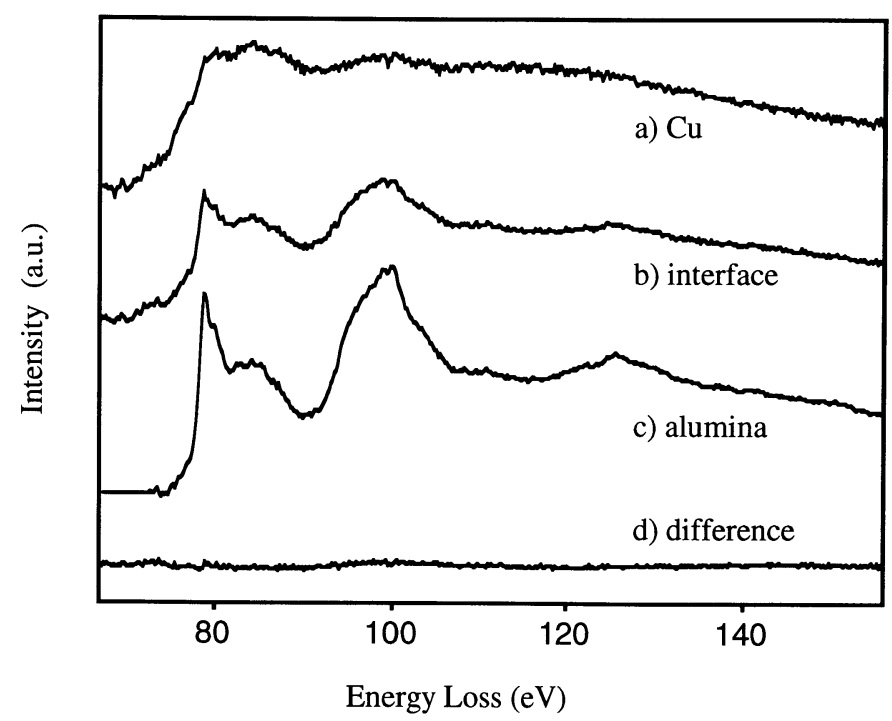

Fig. 7. - Al- $L_{2,3}$ edge and $\mathrm{Cu}-\mathrm{M}_{2,3}$ edge ELNES from MBE grown copper on alumina. The spectra were from a) $\mathrm{Cu}$ near the interface, b) the interface, c) $\mathrm{Al} 2 \mathrm{O} 3$ near the interface. d) is the calculated difference spectrum.

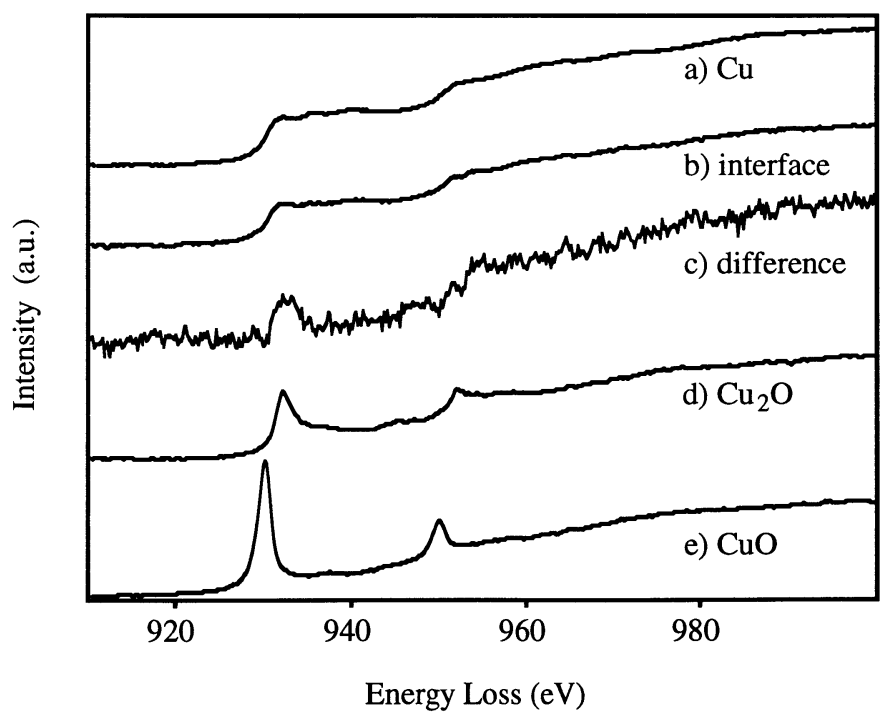

Fig. 8. - Cu- $L_{2,3}$ edge ELNES from MBE grown copper on alumina. The spectra were from a) $\mathrm{Cu}$ near the interface, b) the interface, c) the calculated difference spectrum. The spectra d) cuprous oxide $\mathrm{Cu}_{2} \mathrm{O}$ and e) cupric oxide $\mathrm{CuO}$ were provided by $\mathrm{Hui} \mathrm{Gu}$ (unpublished).

transitions to localized, unoccupied band-gap states in the alumina induced by the metal at the interface. Such features can not be simulated by the MS calculations and therefore they do not appear in the calculated ELNES.

The slight downward shift of the edge onset and the broadening of the main peak at the O-K 
edge in the interface spectrum compared to that in the bulk alumina spectrum could be due to a decrease of the oxygen site symmetry [31]. Similar effects were found in the investigation of amorphous or $\gamma-\mathrm{Al}_{2} \mathrm{O}_{3}$ [31] and $\mathrm{Fe}-\mathrm{Al}_{2} \mathrm{O}_{3}$ interfaces [8].

4.2 $\mathrm{CU} / \mathrm{AL}_{2} \mathrm{O}_{3}$ INTERFACE. - White lines are typical for transition metals and their oxides [32]. They occur from transitions from $2 \mathrm{p}$-states to empty $3 \mathrm{~d}$-states. In metallic copper the $3 \mathrm{~d}$-band is completely filled and no white line occurs. In contrast the white lines observed for $\mathrm{CuO}\left(\mathrm{Cu}^{2+}\right)$ and $\mathrm{Cu}_{2} \mathrm{O}\left(\mathrm{Cu}^{1+}\right)$ (Fig. 8d, e) indicate partly unoccupied 3d-states and possible transitions to these states [32]. To get unfilled 3d-states, a charge transfer from the copper to the oxygen is necessary.

The difference spectrum of the $\mathrm{Cu}-L_{2,3}$ edge shows a shape similar to the reference spectra taken from cuprous oxide $\left(\mathrm{Cu}_{2} \mathrm{O}\right)$ and cupric oxide $(\mathrm{CuO})$ (Fig. 8). No chemical shift, typical of $\mathrm{Cu}^{2+}$, was observed. This indicates that the oxidation state of copper at the interface is +1 . The observed white line in the difference spectrum is associated with an electron transfer from $\mathrm{Cu}$ to O. Therefore, we expected that an interface-specific component exists at the O-K edge, and we found this to be the case (Fig. 9).

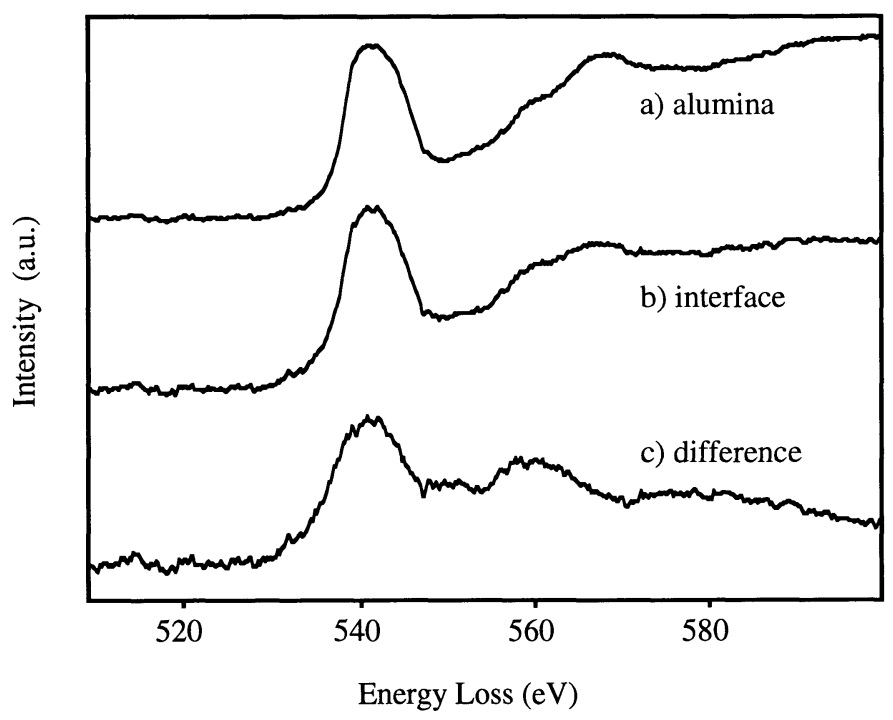

Fig. 9. - O-K edge ELNES from MBE grown copper on alumina. The spectra were from a) $\mathrm{Al}_{2} \mathrm{O}_{3}$ near the interface, $b$ ) the interface and c) the calculated difference spectrum.

We compared the O-K edge difference spectrum with the $\mathrm{O}-\mathrm{K}$ edge of $\mathrm{CuO}$ and $\mathrm{Cu}_{2} \mathrm{O}$, however, no match was found. This could result from the difference between the coordination of the oxygen atoms at the interface to that in $\mathrm{Cu}_{2} \mathrm{O}$ and $\mathrm{CuO}$. Another possibility for the disagreement is that the interfacial oxygen has both $\mathrm{Cu}$ and $\mathrm{Al}$ atoms as next nearest neighbours. A more detailed interpretation of this spectrum requires MS calculations. Furthermore, the agreement between the $\mathrm{Cu}_{2} \mathrm{O}$ reference spectrum and the difference spectrum especially in the energy-loss region above the $\mathrm{Cu}-L_{2}$ edge is not perfect (Fig. 10). This might be again caused by the difference in the local coordination between the interface and that of cuprous oxide. The existence of the white line, however, is mainly an atomic effect modulated by the symmetry of the ligand field. This 


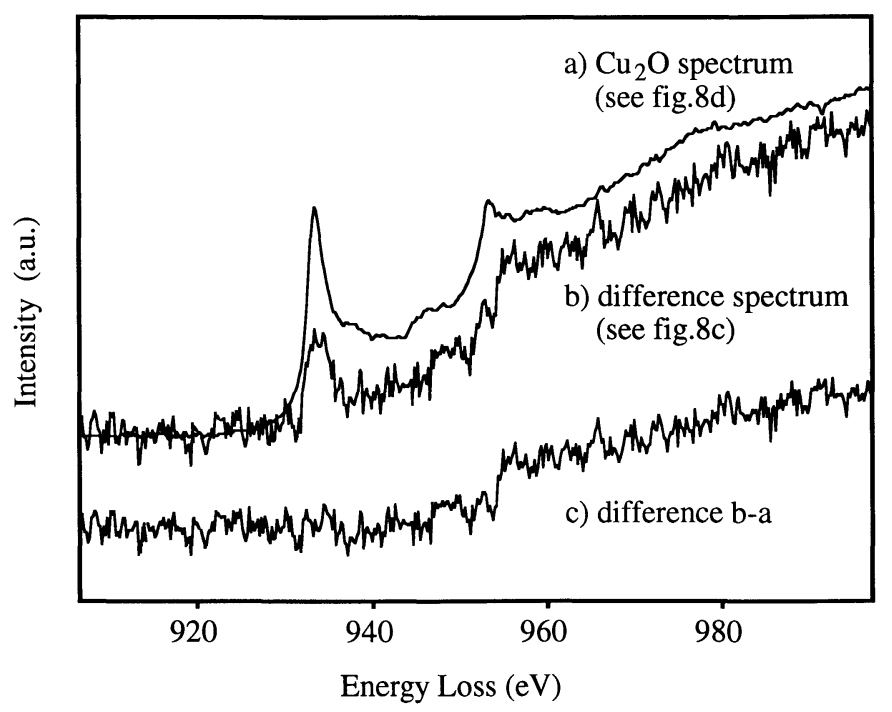

Fig. 10. - Comparison of the Cu- $L_{2,3}$ edge ELNES of the calculated difference spectrum of the MBE grown copper on alumina $b$ ) with the cuprous oxide $\mathrm{Cu}_{2} \mathrm{O}$ a); $c$ ) shows the calculated difference between this spectra.

explains why the differences with the reference spectra are stronger for the $\mathrm{O}-\mathrm{K}$ edge, which is determined strongly by the coordination and type of nearest neighbours.

No interface-specific component exists in the energy region of the Al- $L_{2,3}$ and $\mathrm{Cu}-M_{2,3}$ edge (Fig. 7). We conclude that the Al-atoms are not involved in the bonding and that there is no noticeable change in the local coordination of the $\mathrm{Al}$ atoms. From the results at the $\mathrm{Cu}-L_{2,3}$ edge one might also expect a change at the $\mathrm{Cu}-M_{2,3}$, which was not observed. The differences in the ELNES of the $\mathrm{Cu}-M_{2,3}$ edge for various oxidation states are small [33] and could not be detected in the present work.

The copper-oxygen bonding across the interface and the $\mathrm{Cu}^{1+}$ oxidation state at the interface that we observed is in good agreement with surface sensitive measurements $[20,21]$ and calculations [34] of other investigators. Kasowski et al. [21] have shown that copper bonds to oxygen at a 0.5 monolayer coverage of $\mathrm{Cu}$ on polycrystalline $\mathrm{Al}_{2} \mathrm{O}_{3}$. They base this conclusion on the lower total energy for $\mathrm{Cu}-\mathrm{O}$ bonds than for $\mathrm{Cu}-\mathrm{Al}$ bonds obtained by ab initio total energy pseudofunction calculations. Furthermore, they have calculated the density of states and compared it with their measured UPS data taken for low coverage of $\mathrm{Cu}$. They achieve good correlation between theory and experiment only for the case of $\mathrm{Cu}-\mathrm{O}$ bonds and not for $\mathrm{Cu}-\mathrm{Al}$ bonds. Guo and Møller [20] have studied copper films evaporated on (0001) $\alpha-\mathrm{Al}_{2} \mathrm{O}_{3}$ by AES and REELS using a cylindrical mirror analyzer. Their results also indicate that the bonding is established between the $\mathrm{Cu}$ and $\mathrm{O}$ atoms and an oxidation state of $\mathrm{Cu}^{1+}$. Self-consistent field $\mathrm{X}-\alpha$ scattered wave cluster molecular-orbital models have been constructed by Johnson and Pepper [34]. For their calculations they used a $\mathrm{Cu}\left(\mathrm{AlO}_{6}\right)^{-9}$ cluster representing the $\mathrm{Cu} / \mathrm{Al}_{2} \mathrm{O}_{3}$ interface. They concluded that a chemical bond can be established between the d-orbital electrons of $\mathrm{Cu}$ and the nonbonding $2 \mathrm{p}$ orbital electrons of the oxygen anions on the $\mathrm{Al}_{2} \mathrm{O}_{3}$ surface. In addition to this covalent bonding there is a ionic component associated with a metal-to-oxygen charge transfer at the interface.

Our results are consistent with those derived from surface sensitive experiments. Hence we conclude that in the $\mathrm{Cu} / \mathrm{Al}_{2} \mathrm{O}_{3}$ system the bonding in bulk material is the same as for surface 
layers. Similar results were also found for specimens prepared by infiltration of liquid copper into porous alumina [5]. Therefore, for abrupt interfaces $\mathrm{Cu}-\mathrm{O}$ bonding seems to be independent of the $\mathrm{Cu} / \mathrm{Al}_{2} \mathrm{O}_{3}$ preparation process.

\section{Summary and Conclusion}

We were able to derive information on structural and electronic rearrangements at bulk metalalumina interfaces. We propose simple interfacial structural units for the $\mathrm{Al} / \mathrm{Al}_{2} \mathrm{O}_{3}$ system by comparing the measured $\mathrm{Al}-L_{2,3}$ difference spectrum with the calculated ELNES. The $\mathrm{Al}$ environment at the interface was approximated as a tetrahedral arrangement with a central $\mathrm{Al}$ atom coordinated to three $\mathrm{O}$ atoms and one $\mathrm{Al}$ atom having a larger bond length. For the $\mathrm{Cu} / \mathrm{Al}_{2} \mathrm{O}_{3}$ system our results suggest copper-oxygen bonding across the interface and a $\mathrm{Cu} 1+$ oxidation state of copper at the interface. Both investigations clearly demonstrate that the ELNES can be obtained from internal interfaces of bulk materials in order to characterize them. The method is useful for the study of metal-ceramic interfaces on a nanometer scale.

\section{Acknowledgements}

We acknowledge financial support from the Volkswagen-Stiftung contract I/66790 and the British Council and the Royal Society for travel and research grants to R.B. The help and support of following colleagues is acknowledge: Prof. J. Rödel, Technische Hochschule Darmstadt, provided the $\mathrm{Al} / \mathrm{Al}_{2} \mathrm{O}_{3}$ material and Prof. $\mathrm{R}$. Raj, Cornell University, the $\mathrm{MBE} \mathrm{Cu} / \mathrm{Al}_{2} \mathrm{O}_{3}$ samples, $\mathrm{M}$. Sycha prepared a part of the the $\mathrm{Al} / \mathrm{Al}_{2} \mathrm{O}_{3}$ TEM specimens, Dr. S.K. Streiffer investigated the $\mathrm{Al} / \mathrm{Al}_{2} \mathrm{O}_{3}$ specimen by conventional TEM, Dr. $\mathrm{H}$. Gu provided the reference spectra of $\mathrm{Cu}_{2} \mathrm{O}$ and $\mathrm{CuO}$ (both unpublished). Furthermore we acknowledge helpful discussions with Dr. J. Bruley about the spatial difference technique and the difference spectrum of the $\mathrm{Al} / \mathrm{Al}_{2} \mathrm{O}_{3}$ interface and Dr. H. Gu about the reference spectra.

\section{References}

[1] Rez P. in "Transmission Electron Energy Loss Spectroscopy in Materials Science" ( M.M. Disko, C.C. Ahn and B. Fultz Eds.) The Minerals, Metals and Materials Society, Warrendale (1992) 107-129.

[2] Brydson R., Sauer H. and Engel W. in "Transmission Electron Energy Loss Spectroscopy in Materials Science" (M.M. Disko, C.C. Ahn and B. Fultz Eds.) The Minerals, Metals and Materials Society, Warrendale, (1992) 131-154

[3] Browning N.D., Chisholm M.F. and Pennycook S.J., Nature 366 (1993) 143-146.

[4] Müllejans H. and Bruley J., Ultramicroscopy 53 (1994) 351-360.

[5] Müllejans H. and Bruley J., J. Microsc. (1994), submitted.

[6] Bruley J., Microsc. Microanal. Microst. 4 (1993) 23-39.

[7] Bruley J., Brydson R., Müllejans H., Gutekunst G., Mader W., Knauss D. and Rühle M., J. Mater. Res. 9 (1994) 2574-2583.

[8] Brydson R., Müllejans H., Bruley J., Trusty P., Sun X., Yeomans J. and Rühle M., J. Microsc. (Jan. 1995) in press .

[9] Prielipp H., Knechtel M., Claussen N., Streiffer S.K., Müllejans H., Rühle M. and Rödel J., J. Mat. Sci. Eng. (1994) in press.

[10] Dehm G., Rühle M., Ding G. and Raj R., Phil. Mag. (1994) accepted. 
[11] Naka M., Ultramicroscopy 39 (1991) 128-134.

[12] Timsit R.S., Waddington W.G., Humphreys C.J. and Hutchison J., Ultramicrosopy 18 (1985) 387-394.

[13] Isaacs J.A. and Mortensen A., Metall. Trans. A 23A (1992) 1207-1219.

[14] Vermeersch M., Sporken R., Lambin P. and Caudano R., Surf. Sci. 235 (1990) 5-14.

[15] Mellul S. and Chevalier J. P., Phil. Mag. A 64 (1991) 561-576.

[16] Beraud C., Courbiere M., Esnouf C., Juve D. and Treheux D., J. Mat. Sci. 24 (1989) 4545-4554.

[17] Burgess J.F., Neugebauer C.A., Flanagan G., J. Electrochem. Soc. 122 (1972) 688-690.

[18] Mulder C. and Klomp J.T., J. Phys. C4 (1985) 111-116.

[19] Ernst F., Pirouz P. and Heuer A.H., Phil. Mag. A 63 (1991) 259-277.

[20] Guo Q. and Møller P.J., Surf. Sci. 244 (1991) 228-236.

[21] Kasowski R.V., Ohuchi F.S. and French R.H., Physica B 150 (1988) 44-46.

[22] Rogers K.A., Trumble K.P., Dalgleish B.J. and Reimanis I.E., J. Am. Ceram. Soc. 77 (1994) 2036-2042.

[23] Beraud C., Courbiere M., Esnouf C., Juve D. and Trehaux D., J. Mat. Sci. 24 (1989) 4545-4554.

[24] Guo Q. and Møller P.J., Thin Solid Films 201 (1991) 267-279.

[25] Hirsch P.B., Howie A., Nicholson R.B., Pashley D.W., Whelan M.J., "Electron Microscopy of Thin Crystals" (Krieger Publishing Company, Malabar, Florida, Second Edition, 1977).

[26] Philipp F., Höschen R., Möbus G., Osaki M. and Rühle M., JEOL News 31 (1994).

[27] Strecker A., Salzberger U. and Mayer J., Prakt. Metallogr. 30 (1993) 482-495.

[28] Egerton R.F., "Electron Energy Loss Spectroscopy in the Electron Microscope" (Plenum Press, New York, 1986).

[29] Vvedensky D.D., Saldin D.K. and Pendry J.B., Comput. Phys. Comm. 40 (1986) 421-440.

[30] Brydson R., Williams B.G., Engel W., Lindner T., Muhler M., Schlögl R., Zeitler E. andThomas J.M. , J. Chem. Soc. Far. Trans. 84 (1988) 631-646.

[31] Brytov I.A. and Romashchenko N.Y., Sov. Phys. Solid. State 20 (1977) 384-389.

[32] Leapman R.D., Grunes L.A. and Fejes P.L., Phys. Rew. B 26 (1982) 614-635.

[33] Gu H., private communication.

[34] Johnson K.H. and Pepper S.V., J. Appl. Phys. 53 (1982) 6634-6637. 